\title{
NUTRIÇÃO MINERAL DE PLANTAS ORNAMENTAIS. VII. ESTUDOS DE ADUBAÇÃO NPK NA CULTURA DE GLADÍOLO (Gladiolus grandiflorus, cv. 'Perusi').
}

\author{
Pedro Dantas Fernandes ** \\ Henrique Paulo HaAg \\ SALIM Simão \\ Jairo Ribeiro de Mattos
}

\section{RESUMO}

Três doses de $\mathbf{N}, \mathbf{P}$ e $\mathrm{K}$ foram testadas em culturas de gladiolos (Gladiolus grandiflorus cv. 'Perusi') provenientes de três tamanhos diferentes de bulbos (No 3, No 1 e Jumbo). Todos os tratos culturais necessários foram dispensados aos experimentos cuja instalação se deu em um solo podzolizado da Cooperativa Agrícola de Holambra, em Jaguariúna - SP. Estudaram-se os efeitos de adubação sobre produção de flores, produção de bulbos e de bulbilhos.

A resposta do gladiolo aos niveis de fertilização variou bastante com o tamanho de bulbo plantado. São discutidos os efeitos de cada nutriente sobre as caracteristicas estudadas.

\section{INTRODUÇAO}

Em nossas condições são escassos os trabalhos de nutrição mineral do gladíolo. Em vários países vem sendo conduzidos ensaios, mostrando-se muitas vezes contraditórios por responder de modo diferente à adubação, conforme o solo e clima em que é cultivado, a variedade utilizada e o tamanho de bulbo plantado (GUTAY \& KRONE, 1957; WOLTZ, 1959; VAN DIEST \& FLANNERY, 1963).

Enquanto que McCLELLAN (1954) obteve efeitos negativos com adubações, que chegaram a atrasar o florescimento e piorar a qualidade das

- Parte dos dados da Tese de Doutoramento apresentada pelo primeiro autor a $\mathbf{E}$. S. A. «Luiz de Queiroz» - USP. Entregue para publicaçåo em 30/12/1974.

** Depto de Fitotecnia da F. M. V. A. Jaboticabal.

*** Depto de Química da E. S. A. \&Luiz de Queiroz»

**** Depto de Agricultura e Horticultura da E. S. A. \&Luiz de Quelroz. 
flores, WOLTZ (1959) e WATERS (1965), entre outros, obtiveram boas respostas do gladíolo à adubação.

Segundo WOLTZ (1955) o nitrogênio é responsável pelo número de hastes florais produzidas e pelo número de botões florais por haste, enquanto o potássio influencia diretamente no comprimento da haste.

No presente trabalho são estudados os efeitos de adubação $\mathrm{N}, \mathrm{P}, \mathrm{K}$ em culturas provenientes de bulbos de diferentes tamanhos.

\section{MATERIAL E METODOS}

Instalações dos ensaios

Os experimentos foram instalados em solo pertencente ao Grande Grupo Podzolizado Vermelho Amarelo-orto (PV) (COMISSÃO DE SOLOS, 1960), localizado na Cooperativa Agrícola de Holambra S. A., em Jaguariúna - SP.

Os dados de análise química do solo, realizada segundo CATANI et al. (1955) estão contidos no Quadro 1.

QUADRO 1 - Características químicas do solo em que foram instalados os ensaios.

$\mathrm{pH}$

Carbono (\%)

${ }^{*} \mathrm{PO}_{4}-$ - trocável e. $\mathrm{mg} . / 100 \mathrm{~g}$ de solo

$\mathrm{K}^{+} \quad$ trocável e. $\mathrm{mg} . / 100 \mathrm{~g}$ de solo

$\mathrm{Ca}^{++} \quad$ trocável e. $\mathrm{mg} . / 100 \mathrm{~g}$ de solo

$\mathrm{Mg}++$ trocável e. $\mathrm{mg} . / 100 \mathrm{~g}$ de solo

$\mathrm{A} 1+++$ trocável e. $\mathrm{mg} . / 100 \mathrm{~g}$ de solo

* solúvel em $\mathrm{H}_{2} \mathrm{SO}_{4}-0,05 \mathrm{~N}$

Foram utilizados bulbos de gladíolo (Gladiolus grandiflorus cv. 'Perusi') tipo N.o 3 (3 cm de diâmetro), N.o 1 (4 cm de diâmetro) e Jumbo (6 $\mathrm{cm}$ de diâmetro), todos de mesma idade e obtidos de um mesmo campo de produção. Após preparo conveniente, o terreno foi sulcado a distâncias de $0,60 \mathrm{~m}$ e profundidade de $0,30 \mathrm{~m}$.

Os níveis de nutrientes aplicados no fundo dos sulcos, em torno de $5 \mathrm{~cm}$ abaixo dos bulbos, foram os seguintes:

Sulfato de amônio: $\mathrm{N}_{1}-10 \mathrm{~g} / \mathrm{m}$ linear de sulco

$\mathrm{N}_{2}-15 \mathrm{~g} / \mathrm{m}$ linear de sulco

$\mathrm{N}_{3}-20 \mathrm{~g} / \mathrm{m}$ linear de sulco 
Superfosfato simples: $P_{1}-30 \mathrm{~g} / \mathrm{m}$ linear de sulco

$\mathrm{P}_{2}-45 \mathrm{~g} / \mathrm{m}$ linear de sulco

$\mathrm{P}_{3}-60 \mathrm{~g} / \mathrm{m}$ linear de sulco

Cloreto de Potássio: $\mathrm{K}_{1}-5 \mathrm{~g} / \mathrm{m}$ linear de sulco

$\mathrm{K}_{2}-10 \mathrm{~g} / \mathrm{m}$ linear de sulco

$\mathrm{K}_{3}-15 \mathrm{~g} / \mathrm{m}$ linear de sulco

Os bulbos nos sulcos guardavam entre si uma distância igual ao seu diâmetro. Antes do plantio, que se deu a 17 de agosto de 1972, foram tratados com Benlate.

Aos 15 e 35 dias após brotação, épocas adotadas na prática (FERNANDES, 1972), houve aplicação em cobertura de sulfato de amônio, seguindo os níveis constados anteriormente e de acordo com os tratamentos. Dispensaram-se todos os tratos culturais necessários. Mesmo sendo baixo 0 índice de pH, 5,2 (Quadro 1), não foi feita calagem, observando indicações da literatura segundo as quais os gladíolos vegetem bem em solo com o pH a partir de 5,0 (WOITZ, 1957; NEW ENGLAND GLADIOLUS SCIETY, 1966).

Combinando fatorialmente os três níveis de nitrogênio, fósforo e potássio obteve-se o número de 27 tratamentos, sendo no total três ensaios, um para cada tamanho de bulbo plantado. As parcelas eram constituidas de quatro fileiras de dez bulbos cada, e ao todo 40 bulbos por parcela.

\section{Coleta dos Ensaios}

As hastes florais foram coletadas quando apresentavam o primeiro botão floral se abrindo. Antes do corte processou-se a sua medida da base da planta à extremidade da inflorescência. $\mathrm{O}$ corte foi feito à altura de 15 $\mathrm{cm}$ do solo. A coleta dos bulbos se deu aos 45 dias após o corte das inflorescências, fazendo-se a contagem e pesagem dos bulbos e bulbilhos.

Após a coleta das hastes florais, estas foram divididas em pedúnculo, folhas e botões florais. Considerou-se como pedúnculo floral, a base do eixo floral, livre de folhas, a partir do ponto em que foi cortado até o da emissão da primeira flor. Foram consideradas folhas, aquelas separadas do pedúnculo floral, e como botões florais a extremidade da inflorescência, a partir do ponto de emissão da primeira flor.

Análises Químicas

O material seco constante das divisões feitas na parte aérea e subterrânea das plantas, foi moido em moinho semi-micro «willey», peneira de malha $n .^{\circ} 20$.

Foram feitas análises químicas para nitrogênio, fósforo e potássio, seguindo a metodologia descrita em SARRUGE \& HAAG (1974). 


\section{Análise Estatística}

Para análise estatística foram desdobrados os efeitos lineares e quadráticos, utilizando-se do Teste $\mathrm{F}$ ao nível de $5 \%$ de probabilidade (PIMENTEL GOMES, 1970).

\section{RESULTADOS E DISCUSSÃO}

Parte subterrânea da planta

No quadro 2 são apresentados os valores de Teste $\mathrm{F}$ (5\%) para número de bulbos e de bulbilhos,pesod e matéria fresca de bulbo e de bulbilho e no Quadro 3 as respectivas médias obtidas.

Observa-se inicialmente que o número de bulbos obtidos varia com 0 tamanho do original plantado, sendo em maior quantidade para os de diâmetro maior, por conterem várias gemas. SOUZA (1959) diz que os bulbos grandes podem ser dotados de mais de duas gemas superiores.

De modo geral as maiores respostas foram obtidas pela cultura proveniente do bulbo de menor tamanho (N. $\left.{ }^{\circ} 3\right)$, enquanto que a cultura do tipo N. 1 foi a que menos respondeu à adubação. Estas observações acordam entre outras, com as de KENNETH (1950) WOLTZ (1955), VAN DIEST \& FLANNERY (1963), que citam haver maior exigência de nutrientes por parte de bulbos menores, principalmente devido a sua menor reserva nutricional.

Já em relação ao bulbo de tamanho médio (N. ${ }^{\circ}$ 1) que respondeu menos à adubação, pode ser devido a sua reserva de nutrientes aliada à capacidade de um sistema radicular mais extensivo, segundo WOLTZ (1959). Seguindo igual raciocínio, seria de se esperar uma menor resposta do bulbo Jumbo à adubação. Contudo, isto não ocorre, apesar de sua maior quantidade de reserva, por já estar em final de sua vida útil e menor vitalidade (SOUZA 1959; FERNANDES, 1972) e também por apresentar um sistema radicular menos extensivo (WOLTZ, 1959).

Enquanto que nitrogênio apresentou um maior efeito para número de bulbos e de bulbilhos, o potássio resultou sempre em efeitos lineares, promovendo a obtenção de bulbos e bulbilhos mais pesados e consequentemente com mais reserva. Vários trabalhos citam a importância do potássio na translocação de carbohidratos, tendo inclusive sido demonstrado que plantas de mandioca deficientes em potássio acumulam acúcares na parte aérea, ao contrário das bem supridas neste elemento, em que os açúcares são translocados para as raízes, armazenando-se sob forma de amido (MALAVOLTA et al., 1955; ULRICH \& OHKI, 1966). 


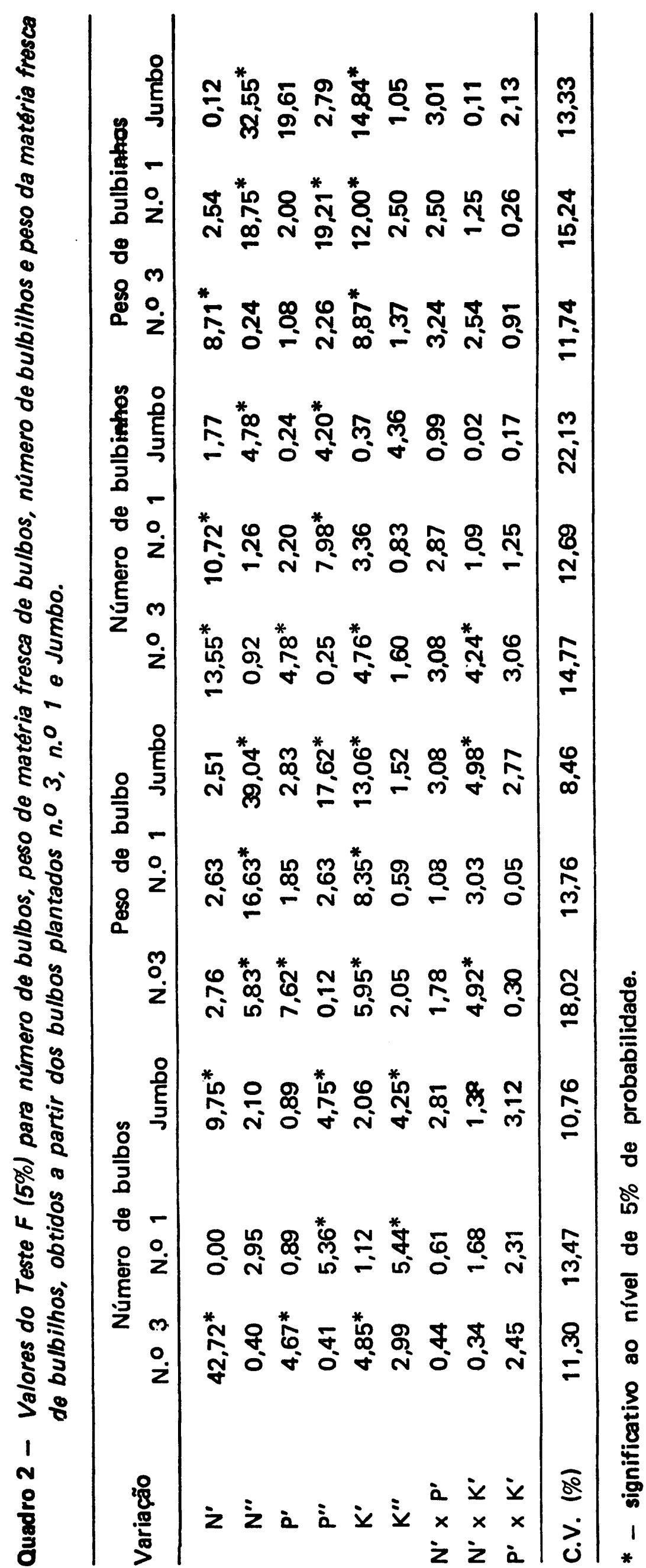




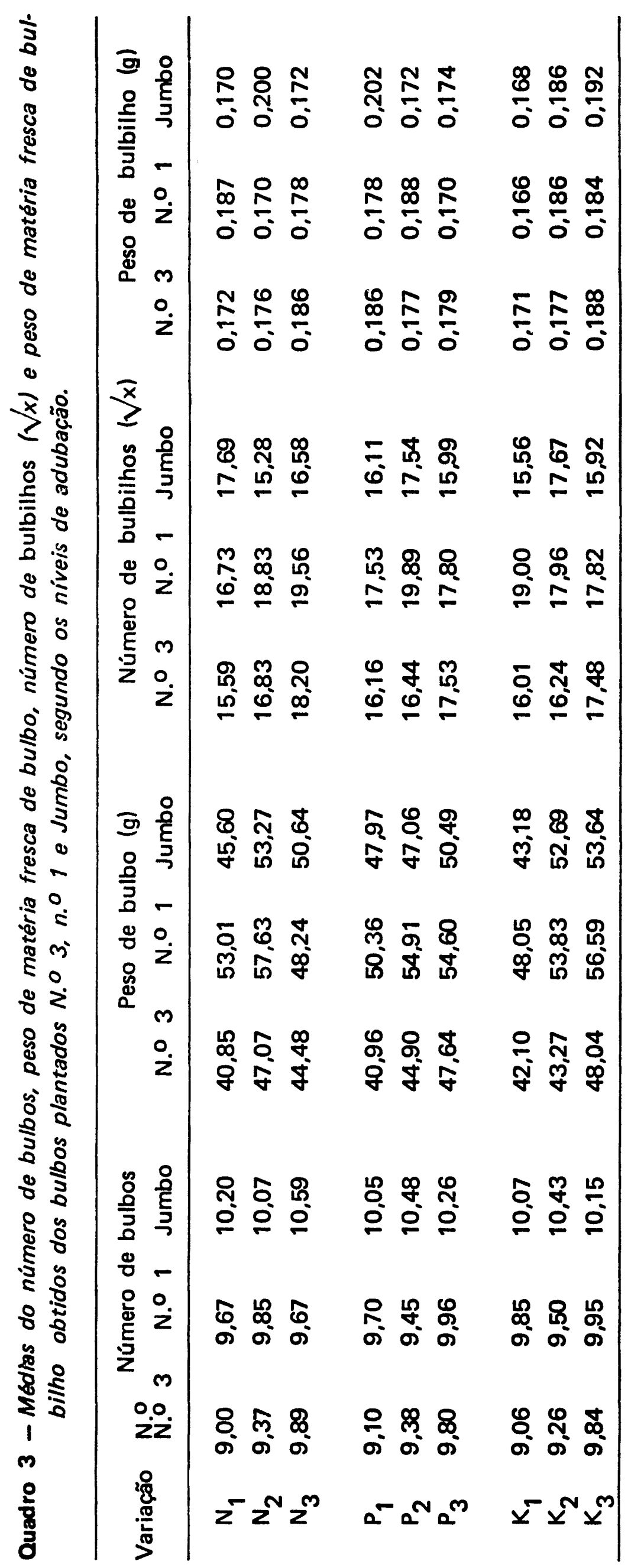


WOLTZ (1959) verificou maior peso de bulbos de gladíolos em altos níveis de potássio, mas sempre quando os níveis de nitrogênio eram também satisfatórios. Embora sem se referir ao tamanho original de bulbo plantado, estas observações vem de acordo aos efeitos da interação N' x K' significativa, observados em relação aos bulbos plantados $\mathrm{N}^{\circ} 3$ e Jumbo.

Com relação ao número de bulbilhos, verifica-se que o tipo Jumbo produziu menor número e $\mathrm{o}$ tipo $\mathrm{N}^{\circ} 1$ o maior número de bulbilhos. $\mathrm{O}$ tipo Jumbo produziu maior número de bulbos, o que não correspondeu ao número de bulbilhos.

Mesmo sendo muito baixo o teor de fósforo no solo (Quadro 1) este foi o elemento a que menos houve resposta.

Parte aérea da planta

Entre os critérios para classificação comercial das hastes florais está o seu comprimento e o número de botões florais por haste (SOUZA, 1959). Nos Quadros 4 e 5 estão respectivamente os valores de Teste $\mathrm{F}$ e as médias de comprimento de haste e de número de botões florais por haste, para as culturas provenientes dos três tamanhos de bulbos plantados e segundo os níveis de adubação.

Verifica-se uma grande variação entre os dados obtidos para os três bulbos plantados, tendo este fato sido observado também por McCLELLAN (1954) que diz haver diferenças do comprimento de haste com o tamanho de bulbo plantado.

Como descrito anteriormente para as características da parte subterrânea, as maiores respostas se deu para o bulbo menor plantado, enquanto que o tipo N.o 1 foi o que menos respondeu. Também o fósforo apresentou menos efeito que os outros elementos.

QUADRO 4 - Valores de Teste F $(5 \%)$ para comprimento de hastes florais e número de botões florais por parcela, de acordo com o bulbo plantado.

\begin{tabular}{|c|c|c|c|c|c|c|}
\hline \multirow[b]{2}{*}{ Variação } & \multicolumn{3}{|c|}{$\begin{array}{l}\text { Comprimento de haste } \\
\text { floral }\end{array}$} & \multicolumn{3}{|c|}{ Número de botões por } \\
\hline & $N=3$ & $N^{\circ} 1$ & Jumbo & $N^{\circ} 3$ & $N^{\circ} 1$ & Jumbo \\
\hline $\mathrm{N}^{\prime}$ & $5,59 *$ & 0,04 & $4,71^{*}$ & $7,17^{*}$ & 0,04 & 1,17 \\
\hline N" & 1,27 & $6,25 *$ & 0,21 & 0,47 & 2,70 & 0,09 \\
\hline$P^{\prime}$ & 0,29 & 2,23 & 0,26 & $5,41^{*}$ & 0,64 & 0,32 \\
\hline P" & 0,00 & 2,63 & 0,02 & 0,19 & 0,21 & 1,93 \\
\hline $\mathbf{K}$ & $5,12 *$ & 0,03 & 2,53 & 0,00 & 0,36 & 1,24 \\
\hline K” & 1,58 & 1,35 & $4,50 *$ & $6,06^{*}$ & 0,66 & $14,54^{*}$ \\
\hline$N^{\prime} \times P^{\prime}$ & 1,20 & 1,04 & 0,82 & 3,11 & 0,74 & 0,32 \\
\hline$N^{\prime} \times K^{\prime}$ & 0,55 & 0,16 & 2,13 & 2,12 & 0,97 & 2,51 \\
\hline $\mathrm{P}^{\prime} \mathrm{x} \mathrm{K}^{\prime}$ & 0,28 & 0,70 & 1,93 & 3,37 & 1,51 & 2,96 \\
\hline C. V. (\%) & 11,83 & 11,09 & 11,63 & 3,90 & 7,61 & 2,93 \\
\hline
\end{tabular}

* - significativo ao nível de $5 \%$ 
QUADRO 5 - Médias de comprimento de haste floral $(\mathrm{cm})$ e número de botões florais por haste, segundo o tamanho do bulbo plantado e o nível de adubação.

\begin{tabular}{|c|c|c|c|c|c|c|}
\hline \multirow{2}{*}{$\begin{array}{l}\text { Variação } \\
\mathbf{N}_{1} \\
\mathbf{N}_{2} \\
\mathbf{N}_{3}\end{array}$} & \multicolumn{3}{|c|}{$\begin{array}{l}\text { Comprimento de haste } \\
\text { floral }(\mathrm{cm})\end{array}$} & \multicolumn{3}{|c|}{$\begin{array}{l}\text { Número de botões por } \\
\text { haste }\end{array}$} \\
\hline & $\begin{array}{l}116,4 \\
118,3 \\
119,9\end{array}$ & $\begin{array}{l}136,4 \\
135,5 \\
136,4\end{array}$ & $\begin{array}{l}128,7 \\
129,6 \\
130,0\end{array}$ & $\begin{array}{l}15,01 \\
15,13 \\
15,45\end{array}$ & $\begin{array}{l}18,01 \\
17,91 \\
18,00\end{array}$ & $\begin{array}{l}17,20 \\
17,16 \\
17,05\end{array}$ \\
\hline $\begin{array}{l}P_{1} \\
P_{2} \\
P_{3}\end{array}$ & $\begin{array}{l}117,0 \\
117,9 \\
118,0\end{array}$ & $\begin{array}{l}136,2 \\
136,5 \\
135,6\end{array}$ & $\begin{array}{l}129,6 \\
129,5 \\
129,2\end{array}$ & $\begin{array}{l}15,05 \\
15,16 \\
15,40\end{array}$ & $\begin{array}{l}17,98 \\
17,98 \\
17,96\end{array}$ & $\begin{array}{l}17,12 \\
17,25 \\
17,04\end{array}$ \\
\hline $\begin{array}{l}\mathbf{K}_{1} \\
\mathbf{K}_{2} \\
\mathbf{K}_{3}\end{array}$ & $\begin{array}{l}116,9 \\
118,8 \\
119,1\end{array}$ & $\begin{array}{l}135,9 \\
136,4 \\
136,0\end{array}$ & $\begin{array}{l}129,4 \\
128,1 \\
130,8\end{array}$ & $\begin{array}{l}15,10 \\
15,43 \\
15,10\end{array}$ & $\begin{array}{l}17,98 \\
17,96 \\
17,96\end{array}$ & $\begin{array}{l}17,21 \\
16,84 \\
17,37\end{array}$ \\
\hline
\end{tabular}

Segundo WOLTZ (1955) o potássio exerce influência sobre o comprimento de hastes florais do gladíolo, o que no presente trabalho foi observado apenas para o bulbo menor ( $\left.\mathrm{N}^{\circ} 3\right)$.

0 bulbo médio (N. $\left.{ }^{\circ} 1\right)$ produziu hastes mais compridas que os outros bulbos. O tipo Jumbo, de bulbos maiores, apesar de ter originado maior número de bulbos e maior número de hastes florais (a ser discutido em seguida), apresentou hastes menores.

Os bulbos de gladíolos podem ser adotados de mais de uma gema e com o aumento de tamanho há possibilidades de ocorrer maior número de gemas (SOUZA, 1959).

Geralmente cada gema origina uma planta e, consequentemente, uma haste floral e um novo bulbo. Foi o que ocorreu no presente trabalho, em cada bulbo formado correspondeu também a uma haste floral.

Assim os dados apresentados para número de bulbos nos Quadros 2 e 3 são os mesmos para número de hastes florais colhidas.

Com relação aos nutrientes, o nitrogênio influenciou significativa e linearmente o número de hastes florais produzidas pelos bulbos $\mathrm{N}^{\circ} 3 \mathrm{Jum}$ bo. Novamente para o bulbo N.o 1 não se obteve ef eito significativo, estando este resultado de acordo com os obtidos por TAMURA \& MEGA (1959), segundo os quais a produção de flores de bulbo de tamanho médio não é afetada por aplicações de fertilizantes. A importância do nitrogênio sobre a maior produção de hastes florais tem sido também relatada por WOLTZ (1955), (1959).

Segundo McCLELLAN (1954) práticas de fertilização para produção quantitativa de flores devem diferir daquelas para produção de bulbos, com o que não concordam os dados do presente trabalho. A diferença não se deveu à produção de flores em quantidade, mas à qualidade da haste 
floral, no que concerne a seu comprimento e número de botões florais por haste, e também à precocidade de produção a ser abordada mais adiante.

Ainda em relação aos Quadros 2, 3, 4 e 5, mesmo não havendo resposta do bulbo No. 1 à fertilização, mesmo assim os valores de peso de bulbos, número de bulbilhos, comprimento de haste e número de botões florais por haste são mais altos que os dos bulbos, indicando ser o mesmo possuidor de um maior vigor.

\section{Precocidade de produção}

Para os estudos de prococidade, a fase de colheita de hastes florais foi dividida em três períodos:

Período A - hastes florais colhidas entre 01 e 13 de novembro de 1972;

Período B - hastes colhidas entre 14 e 17 de novembro de 1972;

Período C - colheita entre 17 e 28 de novembro de 1972.

No Quadro 6 estão contidos os valores de Teste $F(5 \%)$ da análise de colheita de hastes florais e no Quadro 7 as médias de porcentagens de colheita, para os três tamanhos de bulbo plantado e períodos de análise, segundo os tratamentos.

Observa-se para nitrogênio que embora tenham se registrado algumas significâncias, não houve grande influência sobre a colheita, quer através de variações entre bulbos quer entre períodos. Na literatura são contraditórias as referências ao efeito de nitrogênio sobre florescimento de gladíolo. KOSUGI \& KONDO (1960) reportam-se ao atraso de florescimento devido ao aumento de adubação nitrogenada, enquanto que KOSUGI (1960) relata que aumentando-se as doses de nitrogênio ocorre precocidade de produção.

Quanto ao fósforo verifica-se que para os três tamanhos de bulbos, houve um aumento linear do número de hastes florais colhidas no primeiro período, com o aumento de adubação fosfatada. Alguns efeitos significativos registrados nos períodos $\mathrm{B}$ e $\mathrm{C}$ deveram-se ao seu nível mais baixo. Assim, altas doses favorecem uma produção de hastes mais cedo, enquanto que doses menores atrasam o florescimento, o que vem de acordo às observações de KOSUGI (1960) e VAN DIEST \& FLANNERY (1963).

Quanto a potássio, a dose mais elevada concentrou mais a produção no período intermediário de colheita (B), em que se colheu de 50 a $60 \%$ das hastes em apenas cinco dias.

Relacionado ainda aos Quadros 6 e 7 observa-se que quanto menor é o bulbo plantado maior é a dispersão de produção, enquanto que para o tipo Jumbo ocorreu pequena porcentagem de colheita no último período. Estas observações acordam com as de McCLELLAN (1954), segundo as quais plantas provenientes de bulbos maiores florescem antes que as de bulbos menores. 


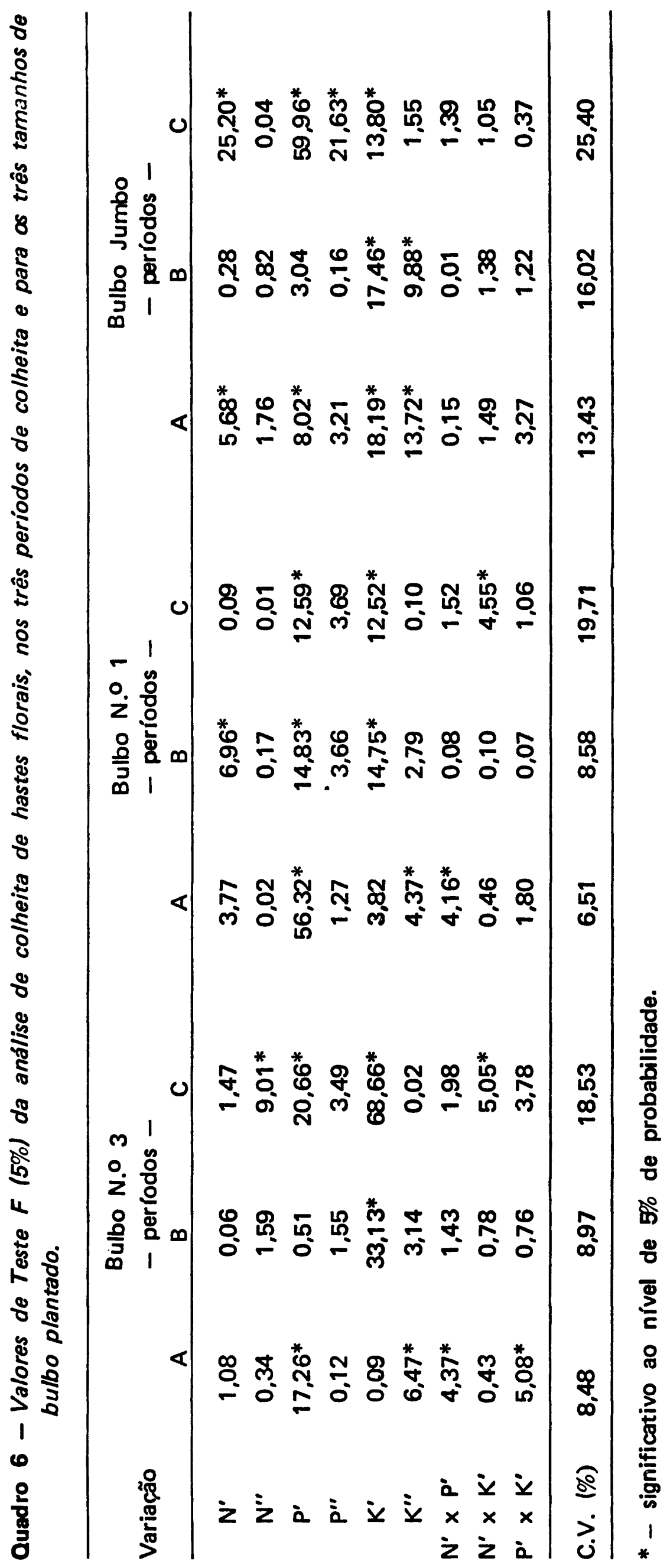


QUADRO 7 - Porcentagem de colheita de hastes florais, para os três tamanhos de bulbo plantado e períodos de análise, segundo os tratamentos.

\begin{tabular}{|c|c|c|c|c|c|c|c|c|c|}
\hline \multirow[t]{2}{*}{ Níveis } & \multicolumn{3}{|c|}{$\begin{array}{l}\text { Bulbo N. }{ }^{\circ} 3 \\
\text { - períodos }\end{array}$} & \multicolumn{3}{|c|}{$\begin{array}{l}\text { Bulbo N. N } 1^{\circ} \\
\text { - períodos - }\end{array}$} & \multicolumn{3}{|c|}{$\begin{array}{l}\text { Bulbo Jumbo } \\
\text { - períodos - }\end{array}$} \\
\hline & A & B & $\mathrm{C}$ & A & B & $\mathrm{C}$ & A & B & C \\
\hline $\mathrm{N}_{1}$ & 35,80 & 37,66 & 26,54 & 47,86 & 36,93 & 15,21 & 38,91 & 54,95 & 6,14 \\
\hline $\mathrm{N}_{2}$ & 35,85 & 35,80 & 28,35 & 48,89 & 37,66 & 13,45 & 38,79 & 51,21 & 10,00 \\
\hline $\mathrm{N}_{3}$ & 37,50 & 37,69 & 24,81 & 45,13 & 42,86 & 12,01 & 33,45 & 53,07 & 13,48 \\
\hline$P_{1}$ & 33,33 & 38,32 & 28,35 & 37,30 & 48,50 & 14,20 & 50,39 & 31,20 & 18,41 \\
\hline$P_{2}$ & 36,59 & 35,81 & 27,60 & 38,76 & 47,37 & 13,87 & 52,28 & 42,49 & 5,23 \\
\hline $\mathrm{P}_{3}$ & 39,19 & 36,93 & 23,88 & 43,36 & 45,90 & 10,74 & 56,59 & 37,64 & 5,77 \\
\hline $\mathrm{K}_{1}$ & 35,47 & 33,53 & 31,00 & 38,79 & 41,81 & 19,40 & 39,52 & 48,89 & 11,59 \\
\hline $\mathrm{K}_{2}$ & 38,43 & 35,06 & 26,51 & 33,96 & 48,13 & 17,91 & 42,03 & 46,63 & 11,34 \\
\hline $\mathrm{K}_{3}$ & 35,53 & 42,51 & 21,96 & 44,79 & 51,86 & 3,35 & 29,83 & 63,56 & 6,61 \\
\hline
\end{tabular}

Concentração de Nutrientes

Concentração de Nitrogênio

No Quadro 8 são tabelados os valores médios de concentração de nitrogênio, em função da matéria seca, nas várias partes em que foram divididas as plantas, segundo o tamanho de bulbo plantado e nível de adubação nitrogenada.

QUADRO 8 - Concentração de nitrogênio em função da matéria seca de várias partes da planta, segundo o bulbo plantado e níveis de adubação nitrogenada.

\begin{tabular}{|c|c|c|c|c|c|c|c|c|c|}
\hline \multirow{3}{*}{ Parte da planta } & \multicolumn{9}{|c|}{ Bulbo plantado } \\
\hline & \multicolumn{3}{|c|}{ N. ${ }^{\circ} 3$} & \multicolumn{3}{|c|}{ N. 1} & \multicolumn{3}{|c|}{ Jumbo } \\
\hline & $\mathrm{N}_{1}$ & $\mathrm{~N}_{2}$ & $\mathrm{~N}_{3}$ & $\mathrm{~N}_{1}$ & $\mathrm{~N}_{2}$ & $\mathrm{~N}_{3}$ & $\mathrm{~N}_{1}$ & $\mathrm{~N}_{2}$ & $\mathrm{~N}_{3}$ \\
\hline Pedúnculo & 0,85 & 1,08 & 1,13 & 0,98 & 1,24 & 1,28 & 1,05 & 1,08 & 1,19 \\
\hline Folhas & 1,93 & 1.94 & 2,05 & 1,61 & 1,83 & 2,00 & 1,96 & 1,97 & 2,20 \\
\hline Botões florais & 2,18 & 2.23 & 2,25 & 2,23 & 2,37 & 2.59 & 2,42 & 2,47 & 2,38 \\
\hline Bulbo & 2,12 & 2.15 & 2,16 & 2,01 & 2,03 & 2,10 & 1,85 & 1,98 & 2,01 \\
\hline
\end{tabular}

Verifica-se inicialmente que são relativamente baixos os teores no pedúnculo e nas folhas, indicando pela fácil translocação do elemento, sua 
maior concentração nas partes mais novas em desenvolvimento, correspondentes a botões florais.

Ocorreu também translocação de nitrogênio para os bulbos, provavelmente sob formas de proteinas, armazenando-se como substâncias de reserva.

WATERS (1965) verificou que quando havia uma ótima produção de bulbos, o seu teor em nitrogênio estava numa faixa de 1,5 a 2,0\%, em função do peso da matéria seca. Pelos dados do presente trabalho observa-se uma variação em torno do teor máximo apresentado por aquele autor.

Concentração de fósforo

Os teores de fósforo, em relação ao peso de matéria seca de várias partes da planta, estão contidos no Quadro 9.

QUADRO 9 - Concentração de fósforo em função da matéria seca de várias partes da planta.

\begin{tabular}{|c|c|c|c|c|c|c|c|c|c|}
\hline \multirow{3}{*}{ Parte da planta } & \multicolumn{9}{|c|}{ Bulbo plantado } \\
\hline & \multicolumn{3}{|c|}{ N. ${ }^{0} 3$} & \multicolumn{3}{|c|}{ N. 1} & \multicolumn{3}{|c|}{ Jumbo } \\
\hline & $P_{1}$ & $\mathrm{P}_{2}$ & $P_{3}$ & $P_{1}$ & $\mathrm{P}_{2}$ & $\mathrm{P}_{3}$ & $P_{1}$ & $\mathrm{P}_{2}$ & $P_{3}$ \\
\hline Pedúnculo & 0,12 & 0,12 & 0,13 & 0,10 & 0,11 & 0,10 & 0,11 & 0,11 & 0,11 \\
\hline Folhas & 0,17 & 0,18 & 0,18 & 0,17 & 0,17 & 0,17 & 0,19 & 0,15 & 0,17 \\
\hline Botões florais & 0,35 & 0,36 & 0,38 & 0,39 & 0,40 & 0,41 & 0,40 & 0,35 & 0,39 \\
\hline Bulbos & 0,36 & 0,40 & 0,40 & 0,37 & 0,38 & 0,39 & 0,37 & 0,38 & 0,40 \\
\hline
\end{tabular}

E bastante evidente a translocação do fósforo para os botões florais, concordando com citações da literatura que se referem à sua concentração em flores, frutos, sementes e tecidos meristemáticos.

Verifica-se, também, um considerável teor de fósforo nos bulbos, o que pode ser explicado pela sua íntima relação com todos os processos que envolvem armazenamento, utilização e transferência de energia (BRINGHAN, 1966; MALAVOLTA, 1967).

Relacionando uma ótima produção de bulbos com o seu teor em fósforo, WATERS (1965), verificou que deveria ser de $0,36 \%$ esse valor.

A concentração de fósforo que proporcionou uma ótima produção de bulbos, obtida por aquele autor $(\mathrm{P}=0,36 \%)$, corresponde à menor produção de bulbos conseguida no presente trabalho, com uso da dose $P_{1}$, segundo Quadro 2, Quadro 3 e Quadro 9. 0 uso de variedades diferentes pode explicar esta variação. 
Por outro lado, os teores de fósforo relatados por HAAG et al. (1970) aproximam-se destes ora apresentados.

Concentração de Potássio

0 Quadro 10 apresenta os teores de potássio em diversas porções da planta, segundo os níveis do nutriente testados e para os três tamanhos de bulbo plantado.

QUADRO 10 - Concentração de potássio, em função do peso da matéria seca de várias partes da planta, segundo o tamanho de bulbo e nível de adubação potássica.

\begin{tabular}{|c|c|c|c|c|c|c|c|c|c|}
\hline \multirow{3}{*}{ Parte da planta } & \multicolumn{9}{|c|}{ Bulbo plantado } \\
\hline & \multicolumn{3}{|c|}{ N. ${ }^{0} 3$} & \multicolumn{3}{|c|}{ N. ${ }^{0} 1$} & \multicolumn{3}{|c|}{ Jumbo } \\
\hline & $\mathrm{K}_{1}$ & $\mathrm{~K}_{2}$ & $\mathrm{~K}_{3}$ & $\mathrm{~K}_{1}$ & $\mathrm{~K}_{2}$ & $\mathrm{~K}_{3}$ & $\mathrm{~K}_{1}$ & $\mathrm{~K}_{2}$ & $\mathbf{K}_{3}$ \\
\hline Pedúnculo & 1,20 & 1,36 & 1,38 & 1,38 & 1,47 & 1,56 & 1,35 & 1,35 & 1,36 \\
\hline Folhas & 2,29 & 2,43 & 2,62 & 2,27 & 2,38 & 2,43 & 2,28 & 2,31 & 2,36 \\
\hline Botões florais & 2,50 & 2,73 & 3,14 & 3,02 & 3,03 & 3,03 & 2,79 & 2,88 & 3,00 \\
\hline Bulbo & 2,38 & 2,54 & 2,73 & 2,41 & 2,50 & 2,68 & 2,46 & 2,49 & 2,73 \\
\hline
\end{tabular}

O potássio é um nutriente bastante móvel dentro da planta, achando-se em grande porcentagem sob a forma iônica no suco celular (ULRICH \& OHKI, 1966). Os teores apresentados no Quadro 10 mostram ter havido translocação para as diversas partes do vegetal. Nota-se porém que, por ocasião do corte das hastes florais, ainda havia uma boa concentração nas folhas. Eram altos os seus teores nos botões florais e, mesmo depois do corte das flores, foi boa a sua concentração nos bulbos. Comparando-se com dados obtidos por WOLTZ (1957), WATERS (1965) e HAAG et al. (1970), atenta-se à grande exigência em potássio pelo cultivar 'Perusi', que respondeu de modo quase sempre crescente às doses de fertilização.

\section{Extração de Nutrientes}

Assim como para a determinação das concentrações, na análise dos nutrientes extraidos não foram consideradas algumas folhas, e base do segmento floral que sobram no campo após o corte da haste floral, também não se consideraram os bulbilhos nem tampouco o bulbo velho plantado.

Como serão discutidos os totais de nutrientes exportados do solo e considerando-se que quase toda a planta sai do campo de cultivo, torna-se importante ser conhecido o número de plantas existentes em 1 hectare, resultantes de respostas às doses de nutrientes testados. 
No Quadro 11 são apresentados o número de plantas obtidas por parcela (A) e sua estimativa para 1 hectare (B). Essa estimativa se baseou no espaçamento entre bulbos que foi igual ao seu diâmetro, variando portanto com o tamanho de bulbo plantado.

\section{Extração de Nitrogênio}

O Quadro 12 expõe os dados de extração de nitrogênio (mg) contidos nas várias partes de uma planta de gladíolo, proveniente dos tamanhos diferentes de bulbo e de acordo com as doses de adubação nitrogenada. Também são apresentados os valores totais de extração média por planta.

QUADRO 11 - Número de plantas obtidas por parcela (A) e sua estimativa para 1 hectare (B), segundo a dosagem de nutriente $\mathrm{e}$ o tamanho de bulbo plantado.

\begin{tabular}{|c|c|c|c|c|c|c|}
\hline Dosagem & $\begin{array}{c}\text { Bulbo } \\
\text { (A) }\end{array}$ & $\begin{array}{r}N^{0} \quad 3 \\
(B)\end{array}$ & $\begin{array}{l}\text { Bulbo } \\
\text { (A) }\end{array}$ & $\begin{array}{r}\text { N.o } 1 \\
\text { (B) }\end{array}$ & $\begin{array}{l}\text { Bulbo } \\
\text { (A) }\end{array}$ & $\begin{array}{c}\text { Jumbo } \\
\text { (B) }\end{array}$ \\
\hline$N_{1}$ & 9,00 & 298.800 & 9,67 & 250.815 & 10,20 & 211.650 \\
\hline $\mathrm{N}_{2}$ & 9,37 & 311.084 & 9,85 & 255.484 & 10,07 & 208.952 \\
\hline $\mathrm{N}_{3}$ & 9,89 & 328.338 & 9,67 & 250.815 & 10,59 & 219.742 \\
\hline$P_{1}$ & 9,10 & 302.120 & 9,70 & 251.593 & 10,05 & 208.537 \\
\hline $\mathrm{P}_{2}$ & 9,38 & 311.416 & 9,45 & 245.109 & 10,48 & 217.460 \\
\hline $\mathrm{P}_{3}$ & 9,80 & 325.360 & 9,96 & 258.337 & 10,26 & 212.895 \\
\hline $\mathrm{K}_{1}$ & 9,06 & 300.792 & 9,85 & 255.484 & 10,07 & 208.952 \\
\hline $\mathrm{K}_{2}$ & 9,26 & 307.432 & 9,50 & 246.406 & 10,43 & 216.422 \\
\hline $\mathrm{K}_{3}$ & 9,84 & 226.688 & 9,95 & 258.078 & 10,15 & 210.612 \\
\hline
\end{tabular}

A primeira observação verifica-se que em geral o conteúdo em nitrogênio, nas diversas partes da planta, aumentou com o nível de adubação estudado, e que os bulbos armazenam mais de um terço do total de nitrogênio presente em toda a planta.

Considerando-se, que, através do sistema de colheita, a planta sai quase que por inteira do campo de cultivo, nota-se que é considerável o total exportado do nutriente.

Os totais de nitrogênio exportado, em $\mathrm{kg} / \mathrm{ha}$, de acordo com o tamanho de bulbo e as doses testadas, acham-se tabelados no Quadro 13. Os números entre parênteses correspondem à contribuição da quantidade armazenado no bulbo.

Numa adubação de restituição deve ser considerada a contribuição em nitrogênio de cada bulbo plantado. Vale salientar ainda que nesses totais de nitrogênio não está incluido o que contém os bulbilhos, raízes, e 


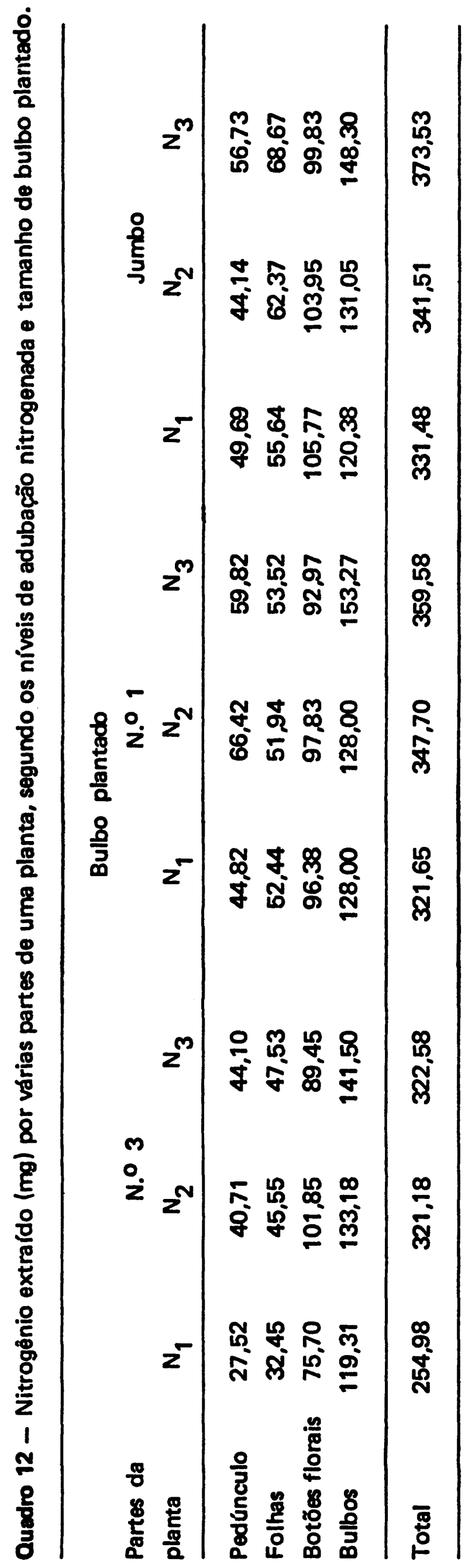


parte de haste e folhas que ficam no solo após a colheita das flores para o comércio.

Quadro 13 - Totais de nitrogênio ( $\mathrm{kg} / \mathrm{ha}$ ) exportado do solo, de acordo com a dose de adubação nitrogenada e o tamanho de bulbo plantado.

\begin{tabular}{lccc}
\hline Bulbo plantado & $\mathrm{N}_{1}$ & $\begin{array}{c}\text { Dose de } \\
\text { nitrogênio } \\
\mathrm{N}_{2}\end{array}$ & $\mathrm{~N}_{3}$ \\
\hline $\mathrm{N}^{\circ} 3$ & 76,19 & 99,91 & 105,92 \\
$\mathrm{~N}^{\circ} 1$ & $(35,65)^{*}$ & $(41.43)$ & $(46,46)$ \\
Jumbo & 80,67 & 88,83 & 90,19 \\
& $(32,10)$ & $(33,60)$ & $(28,44)$ \\
& $(25,16$ & 71,36 & 82,08 \\
& $(25,48)$ & $(27,38)$ & $(32,59)$ \\
\hline
\end{tabular}

* = contribuição des bulbos.

Verifica-se portanto que apesar da grande exportação de nitrogênio, com a instalação de uma nova cultura boa parte desse nutriente poderia voltar ao solo. Mas, tecnicamente não é recomendável o plantio de gladíolos em uma mesma área por dois anos seguidos devido a problemas fitossanitários.

Observa-se que há uma relação direta entre o nível de adubação utilizado e total de nitrogênio exportado, não só pelo aumento de seu teor na planta, como também por sua maior produção.

Segundo dados obtidos por HAAG et al. (1970) com a variedade de gladíolo 'Itapetininga', cultivada em solução nutritiva, até aos 40 dias de idade uma planta extrai cerca de $100 \mathrm{mg}$ de nitrogênio. Observa-se no Quadro 12, que a menor quantidade de nitrogênio presente no bulbo é de $119,31 \mathrm{mg}$, portanto suficiente para o desenvolvimento inicial da planta, sem necessidade de uma adubação nitrogenada no plantio.

\section{Extração do Fósforo}

O Quadro 14 mostra a quantidade de fósforo em $\mathrm{mg}$, contida em várias porções de uma planta de gladíolo, média de três repetições, conforme a dose testada de adubação fosfatada e o tamanho de bulbo utilizado no plantio. Também são apresentados os totais de fósforo extraído.

Quanto maior o bulbo, maior é a extração de fósforo pela planta. 0 conteúdo em fósforo do bulbo aumentou sempre que houve um aumento da dose enquanto que, nas outras partes, não houve um acréscimo correspondente, em geral diminuindo o conteúdo em fósforo com a aplicação de seu nível mais alto $\left(P_{3}\right)$.

Aliadas estas observações com os dados abordados em vários ítens anteriores e apesar de sua importância, como na precocidade de produção de flores por exemplo, o gladíolo, através do cultivar utilizado nos presentes ensaios, não se mostra muito exigente em fósforo. 
QUADRO 14 - Fósforo contido em várias partes de uma planta (mg) segundo os níveis de adubação e tamanho de bulbo.

\begin{tabular}{|c|c|c|c|c|c|c|c|c|c|}
\hline \multirow{2}{*}{$\begin{array}{l}\text { Partes da } \\
\text { planta }\end{array}$} & \multicolumn{9}{|c|}{ Bulbo plantado } \\
\hline & $P_{1}{ }^{N^{\circ}}$ & ${ }^{3} \mathrm{P}_{2}$ & $\mathbf{P}_{3}$ & $P_{1}$ & $\begin{array}{c}N_{0} \overline{1} \\
P_{2}\end{array}$ & $\mathrm{P}_{3}$ & $P_{1}$ & $\mathrm{P}_{2}$ & $\underset{\mathbf{P}_{3}}{\text { Jumbo }}$ \\
\hline Pedúnculo & 4,11 & 4,31 & 4,28 & 5,16 & 5,20 & 4,57 & 4,86 & 5,34 & 4,56 \\
\hline Folhas & 3,86 & 4,59 & 3,74 & 5,25 & 5,32 & 4,86 & 5,34 & 5,40 & 5,41 \\
\hline Botões florais & 15,00 & 14,46 & 13,86 & 15,70 & 16,70 & 15,89 & 16,86 & 16,65 & 16,18 \\
\hline Bulbos & 23,18 & 24,51 & 28,13 & 26,10 & 28,39 & 30,05 & 29,10 & 30,05 & 32,19 \\
\hline Total & 46,15 & 47,87 & 50,01 & 52,21 & 55,61 & 55,37 & 56,16 & 57,44 & 58,34 \\
\hline
\end{tabular}

Usando-se dos mesmos valores de número de plantas/ha apresentados no Quadro 11, para cada tamanho de bulbo plantado, é apresentado 0 Quadro 15, em que são expostas as quantidades de fósforo ( $\mathrm{kg} / \mathrm{ha}$ ) exportado do solo através da colheita de hastes florais e de bulbos. Os dados entre parênteses correspondem à contribuição dos bulbos.

Observa-se uma grande exportação de fósforo, em comparação com outras culturas (HAAG \& SARRUGE, 1971) sempre crescente com o nível de fertilização utilizado, para um mesmo tamanho de bulbo. Os bulbos foram os principais contribuintes na nutrição da planta, pois continham a metade do total do fósforo exportado, fazendo com que o nutriente que é exportado pela planta não saia apenas do solo.

Pelos dados do Quadro 15 verifica-se, ainda, que o total de fósforo exportado é maior para o bulbo N. ${ }^{\circ} 3$, diminuindo com o aumento de tamanho do bulbo plantado. Isto se deve a que em um hectare, diminui bastante o número de bulbos tipo Jumbo (de maior diâmetro) plantados, conforme se depreende do Quadro 11, baixando portanto a quantidade de fósforo que sai do solo.

QUADRO 15 - Totais de fósforo ( $\mathrm{kg} / \mathrm{ha}$ ) exportado do solo de acordo com a dose de adubação fosfatada e o bulbo plantado.

\begin{tabular}{llcc}
\hline & & Dosagens de fósforo & $P_{2}$ \\
Bulbo plantado & $P_{1}$ & $P_{3}$ \\
\hline No 3 & 13,94 & 14,91 & 16,34 \\
No 1 & $(7,00) *$ & $(7,63)$ & $(9,15)$ \\
& 13,14 & 13,63 & 14,30 \\
Jumbo & $(6,57)$ & $(6,96)$ & $(7,76)$ \\
& 11,71 & 12,49 & 12,50 \\
& $(6,07)$ & $(6,53)$ & $(6,85)$ \\
\hline
\end{tabular}

* = con`ribuição dos bulbos. 


\section{Exportação de Potássio}

Os dados de extração de potássio por uma planta de gladíolo, através de seu conteúdo em folhas, pedúnculo floral, botões florais e bulbos, estão contidos no Quadro 16. Também são apresentados os totais de extração (mg) por planta, de acordo com o tamanho de bulbo plantado e o nível testado de adubação potássica. 


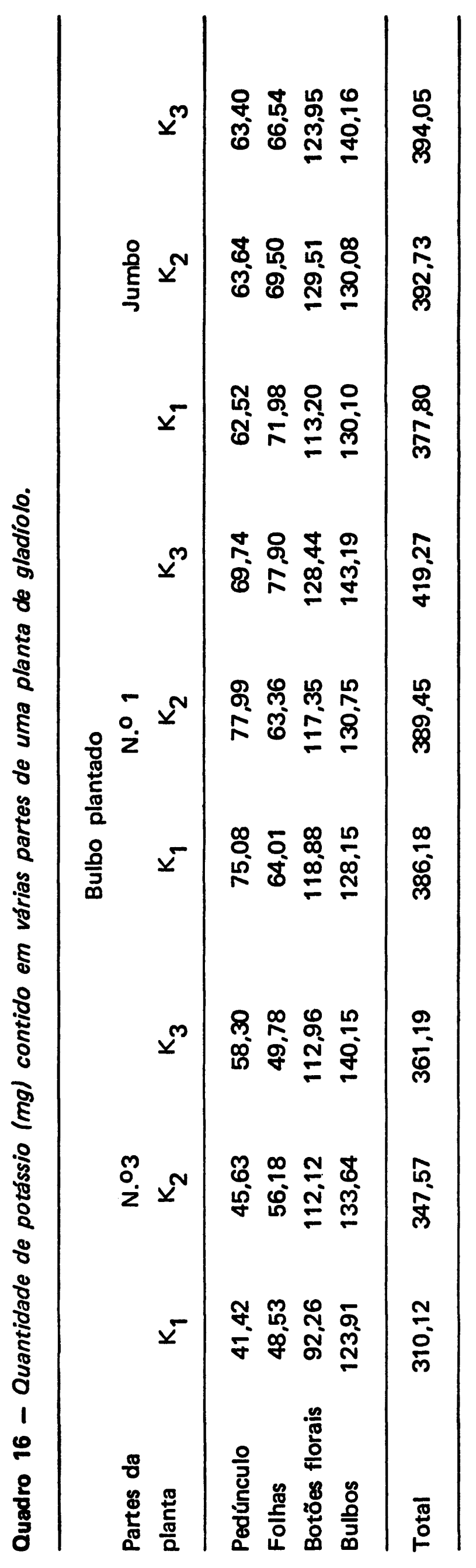


Comparados estes valores com os de Quadros anteriores, vê-se que o potássio é o elemento extraído em maior quantidade por uma planta de gladíolos, o que concorda com os dados relatados por HAAG et al. (1970). Contudo, estes autores encontram um valor maior para a extração de potássio $(586,10 \mathrm{mg} /$ planta), porque consideraram todas as partes da planta, tendo trabalhado com outra variedade e em condições de solução nutritiva.

Entre os tamanhos de bulbo não houve grandes diferenças no total do nutriente extraído. Entretanto variou o conteúdo em potássio entre as doses estudadas, sendo maior com a dose mais alta, e sendo por outro lado, os botões florais e os bulbos os principais armazenadores.

Para se ter uma idéia da exportação de potássio, foram feitas estimativas para 1 hectare, apresentando-se no Quadro 17 os totais do nutriente que deixam o solo de cultivo, em $\mathrm{kg} / \mathrm{ha}$, e entre parênteses a quantidade de potássio que conteriam os bulbos.

QUADRO 17 - Totais de potássio exportado ( $\mathrm{kg} / \mathrm{ha})$, de acordo com os níveis de adubação potássica e o bulbo piantado.

\begin{tabular}{|c|c|c|c|}
\hline Bulbo plantado & $\mathrm{K}_{1}$ & $\begin{array}{l}\text { Dose de potássio } \\
\mathbf{K}_{2}\end{array}$ & $\mathrm{~K}_{3}$ \\
\hline No 3 & $\begin{array}{c}93,28 \\
(37,27) *\end{array}$ & $\begin{array}{l}106,85 \\
(41,08)\end{array}$ & $\begin{array}{l}117,99 \\
(45,79)\end{array}$ \\
\hline No 1 & $\begin{array}{c}98,66 \\
(32,74)\end{array}$ & $\begin{array}{c}95,96 \\
(32,22)\end{array}$ & $\begin{array}{l}108,20 \\
(36,95)\end{array}$ \\
\hline Jumbo & $\begin{array}{c}78,94 \\
(27,18)\end{array}$ & $\begin{array}{c}85,00 \\
(28,15)\end{array}$ & $\begin{array}{c}82,99 \\
(29,52)\end{array}$ \\
\hline
\end{tabular}

* = contribuição dos bulbos.

Em geral, a contribuição dos bulbos é de um terço do total de potássio exportado.

Verifica-se também quanto a potássio, como ocorrido com nitrogênio e fósforo, que o total exportado diminuiu com o uso de bulbo de maior tamanho. Como explicado anteriormente, deve-se o fato ao menor número de bulbos por hectare, existente numa cultura proveniente de bulbo Jumbo em relação a de bulbo $N^{\circ} 3$.

\section{CONCLUSÓES}

a - a resposta do gladíolo a nitrogênio, fósforo e potássio varia com o tamanho de bulbo plantado;

b - cultura proveniente de bulbos pequenos é a mais exigente e do bulbo médio (N.० 1) a menos exigente; 
c - a principal influência do fósforo é sobre precocidade de produção;

d - o nitrogênio influi na produção de bulbos, bulbilhos, e no maior comprimento de haste floral;

e - potássio proporciona maior peso de bulbos e de bulbilhos e tende a concentrar mais a produção em um curto período de colheita;

f - a produção de flores por culturas provenientes de bulbos menores se estende por um período mais longo;

g - bulbos de tamanho médio (N..$^{\circ}$ ) tem maior vigor que bulbos pequenos e bulbo Jumbo;

$\mathrm{h}$ - o conteúdo em nitrogênio, fósforo e potássio de bulbos de gladíolos é suficiente para o desenvolvimento das plantas por 30 a 40 dias de idade.

\section{SUMMARY}

MINERAL NUTRITION OF ORNAMENTAL PLANTS. VII STUDIES ON $\mathrm{N}, \mathrm{P}, \mathrm{K}$ FERTILIZATION OF GLADIOLUS.

Studies on N, P. K fertilization of Gladiolus (Gladiolus grandiflorus, cv. 'Perusi').

At the Agricultural Cooperative of Holambra, Jaguariúna SP, experiments with gladiolus were conducted with the objective of studying the effects of increasing dosis of $\mathrm{N}, \mathrm{P}$ and $\mathrm{K}$ on the floral stems and corms production.

The response of gladiolus to nitrogen, phosphorus and potassium varied with the size of the corm that was planted. The effects of each nutrient on several characteristics of plants are discussed.

\section{LITERATURA CITADA}

BINGHAM, F. T. 1966 - Phosphorus. Em Diagnostic Criteria for Plants and Solls, pp 324-361, ed. H. D. Chapman. Univ. California, Div. Agric. Sciences.

CATANI, R. A.; J. R. GALLO \& H. GARGANTINI. 1955 - Amostragem de Solos, Métodos de Análises, Interpretação e Indicações Gerais para Fins de Fertilidade. Bol. n.9 69, Inst. Agron. de Campinas, Campinas, S. P..

COMISSAO DE SOLOS. 1960 - Levantamento de Reconhecimento dos Solos Mo Estado de São Paulo. Centro Nacional de Ensino e Pesquisas Agronômicas. Bol. n.॰ 12. Rio de Janeiro. $634 \mathrm{pp}$.

FERNANDES, P. D. 1972 - Cultura de Gladiolos. F. M. V. A. Jaboticabal. S. P., 35 pp. (mimeografado).

GUTTAY, J. R. \& P. R. KRONE. 1957 - The Effect of Rates of Different Fertilizers on the Flowering and Corm Production of Gladiolus over two Seasons. Mich. Quart. Bull., 39 (3) : 424-31.

HAAG, H. P.; G. D. OLIVEIRA \& J. R. MATTOS. 1970 - Nutrição Mineral de Plantas Ornamentais. I. Absorção de Nutrientes pela Cultura de Gladiolos. Anais da E. S. A. «Luiz de Queiroz», XXVII : 125-41. 
HAAG, H. P. \& J. R. SARRUGE. 1971 - Nutrição Mineral das Plantas Depto. Química. E. S. A. «Luiz de Queiroz». (mimeografado).

KENNETH, P. 1950 - Gladiolus. Em: Florist Crop Production and Marketing, pp. 540-541. Cornell Univ. Ithaca. New York.

KOSUGI, J. 1960 - Studies on Blindness in Gladiolus. VI. Effects of Fertilizer Treatment on Flowering in Gladiolus. J. Hort. Ass. Japan, $29: 77-82$. (Hortic. Abstracts, 31 : 1117).

\& M. KONDO. 1961 - Studies on Blindeness in Gladiolus. VIII. Effects of Nutritional Treatments on Flowering and Blindness in Gladiolus Grown from Cormels. J. Hort. Ass. Japan, $30: 89-92$. (Hortc. Abstracts, $32: 1217$ ).

MALAVOLTA, E.; E. A. GRANER; T. COURY; BRASIL SOBRINHO, M. O. C.; J. A. C. PACHECO. 1955 - Studies on the Mineral Nutrition of Cassava (Manihot utilissima, Pohl). Plant. Physiology, $30: 81-2$.

MALAVOLTA, E. 1967 - Manual de Química Agrícola. 2.* ed. Biblioteca Agronómica «Ceres», S. Paulo.

MCCLELLAN, W. D. 1954 - Fertilization Further Experiments with Fertilizers for Gladiolus. The Gladiolus: 66-84.

NEW ENGLAND GLADIOLUS SOCIETY. 1966 - Soils and Fertilizers in Relation to Culture of Gladiolus. The Gladiolus: 179-84.

PIMENTEL GOMES, F. 1970 - Curso de Estatística Experimental. E. S. A. «Luiz de Queiroz», Piracicaba, S. P..

SARRUGE, J. R. \& H. P. HAAG. 1974 - Análise Quámica de Plantas. Depto. Química E. S. A. «Luiz de Queiroz», U. S. P., Piracicaba, S. P..

SOUZA, H. M. 1959 - A Cultura de Gladíolus. Inst. Agronômico Estado de São Paulo. Campinas, S. P., 16 pp.

TAMURA, J. \& K. MEGA. 1959 - Yelds of Gladiolus Flowers and Corms Supplied with Differential Nutrients. Bull. Univ. Osaka, Pref. Ser. B., 9:41-7. (Hortic. Abstracts, $33: 3377$ ).

ULRICH, A. \& K. OHKI. 1966 - Potassium. Em: Diagnostic Criteria for Plants and Soils, pp. 362-393, (ed.) H. D. Chapmann, University of California, Div. Agricultural Sciences.

VAN DIEST, A. \& R. L. FLANNERY. 1963 - The Nutritive Requeriments of Gladiolus in New Jersey Soils. Proc. Amer. Soc. Hort. Sci. 82:494-503.

WATERS, W. E. 1965 - Nutrient Requeriments of Gladiolus Cormels on Sandy Soils of Florida. Proc. Soil Sci. Soc. Fla., $25: 59-63$.

WOLTZ, S. S. 1955 - Effect of Differential Supplies of Nitrogen, Pottassium and Calcium on Quality and Yield of Gladiolus Flowers and Corms. Proc. Amer. Soc. Hort. Sci., 65 : 427-35.

. 1957 - A Soil Improvement Program. The Gladiolus: 124-8.

1959 - Fertilization of Gladiolus. The Gladiolus: 177-87. 